03

\title{
Отечественные разработки ИК оптических материалов на основе твердых растворов галогенидов серебра и одновалентного таллия
}

\author{
(С) Л.В. Жукова, А.Е. Львов, А.С. Корсаков, Д.Д. Салимгареев, В.С. Корсаков \\ Уральский федеральный университет имени первого Президента России Б.Н. Ельцина, \\ 620002 Екатеринбург, Россия \\ e-mail: I.v.zhukova@urfu.ru
}

Поступила в редакцию 06.06.2018 г.

В окончательной редакции 13.07.2018 г.

\begin{abstract}
Выполнен обзор современного развития волоконной оптики для среднего инфракрасного диапазона спектра $(2.0-50.0 \mu \mathrm{m})$. Обоснована задача по разработке инфракрасных (ИК) световодов с расширенным в более длинноволновую область спектра рабочим диапазоном, обладающих также повышенной радиационной стойкостью. Проведено исследование диаграмм состояния квазибинарных систем $\mathrm{AgBr}-\mathrm{TII}$ и $\mathrm{AgBr}-\mathrm{TlBr}_{0.46} \mathrm{I}_{0.54}$ четырехкомпонентной системы $\mathrm{AgBr}-\mathrm{AgI}-\mathrm{TlBr}-\mathrm{TlI}$. Выявлены области гомогенности существования твердых растворов. Разработана экспериментальная методика для определения показателя преломления в зависимости от длины волны спектроскопическим методом для кристаллов новых составов. Выявлена стойкость исследуемых материалов к ионизирующему излучению. Проведено моделирование фотонно-кристаллических структур на основе рассматриваемых систем галогенидов металлов и изготовлены методом экструзии одномодовые световоды смоделированной структуры с увеличенным полем моды. Определен спектральный диапазон работы световодов системы $\mathrm{AgBr}-\mathrm{TII}$, который составляет от 4 до $25 \mu \mathrm{m}$. Рассмотрены варианты использования полученных ИК световодов.
\end{abstract}

DOI: $10.21883 /$ OS.2018.12.46936.156-18

\section{Введение}

В 1979 г. в волоконных световодах из кварцевых стекол были достигнуты максимально низкие оптические потери [1]. В настоящее время активно развивается второе поколение материалов для волоконной оптики, которые позволяют передавать излучение в более длинноволновой инфракрасной (ИК) области спектра.

Наиболее перспективными материалами для изготовления световодов среднего ИК диапазона спектра $(2.0-50.0 \mu \mathrm{m})$ являются кристаллы на основе твердых растворов галогенидов серебра [2-7], твердых растворов галогенидов серебра и одновалентного таллия [8], халькогенидные [9-11] и фторидные стекла [12,13], стекла на основе оксида германия [14] и монокристаллы сапфиpa $[15,16]$, а также полые волокна [17-19], поэтому их активно испытывают для новых применений в различных областях науки и техники (рис. 1).

В 1981 г. на Пышминском опытном заводе „Гиредмет“, ныне „Уралредмет“ (г. Верхняя Пышма, Свердловская область), по просьбе нобелевского лауреата А.М. Прохорова, академиков РАН Е.М. Дианова и Г.Т. Петровского впервые были получены высокочистые кристаллы $\mathrm{AgCl}, \mathrm{AgBr}$ и твердые растворы системы $\mathrm{AgCl}-\mathrm{AgBr}$, из которых методом экструзии в ИОФАН и ГОИ им. С.И. Вавилова получали мировой новизны гибкие световоды с уникальными свойствами для среднего ИК диапазона спектра [23]. В это же время впервые в СССР был организован промышленный выпуск указанных кристаллов под руководством разработчиков этих технологий Л.В. Жуковой и главного инженера завода Ф.Н. Козлова.

В настоящее время из кристаллов данной системы изготавливают световоды в Научном центре волоконной оптики РАН. За рубежом данной тематикой занимаются много лет в Тель-Авивском университете под руководством А. Катцира [24-26]. Немецкие фирмы CeramOptec GmbH [20] и Art Photonics GmbH [21] выпускают волоконно-оптическую продукцию на основе галогенидсеребряных световодов для различных областей науки и техники, в том числе для биотехнологий и лазерной медицины.

Недостатком галогенидсеребряных световодов является эффект старения, связанный с фоточувствительностью, а также они не применимы в условиях повышенной радиации. Тем не менее твердые растворы системы $\mathrm{AgCl}-\mathrm{AgBr}$, прозрачные от 0.4 до $30.0 \mu \mathrm{m}$, являются единственными нетоксичными, негигроскопичными и пластичными кристаллами, предназначенными в основном для получения поликристаллических ИК волокон.

Аналогичными свойствами обладают кристаллы системы TlBr-TII ( $\mathrm{TlBr}_{0.46} \mathrm{I}_{0.54}$ - КРС-5) [27-29]. Но световоды на их основе со временем разрушаются вследствие рекристаллизации, что исключает их использование в ИК волоконной оптике, несмотря на радиационную стойкость и прозрачность кристаллов в спектральном диапазоне от 0.4 до $45.0 \mu \mathrm{m}$.

Необходимость расширения рабочего спектрального диапазона световодов от ближней ИК области 

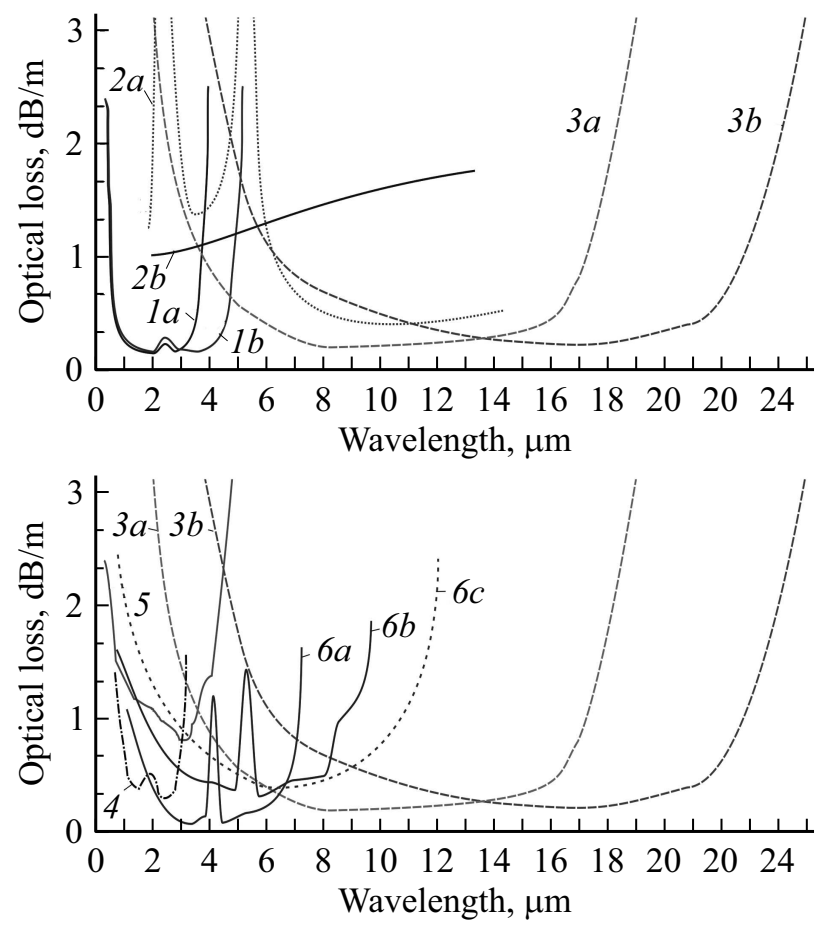

Рис. 1. Оптические свойства ИК световодов: $1 a-$ фтороцирконатные (флюоридные) [12,13], $1 b-$ на основе $\mathrm{InF}_{4}$ [12], $2 a$ - полые JTHWCH [17], 2d - полые JTHWEH [17], $3 a$ - галогенидсеребряные $\mathrm{AgCl}-\mathrm{AgBr}$ [2-7,20-22], $3 b-$ галогенидсеребряные $\mathrm{AgBr}-\mathrm{TII}[8], 4$ - на основе $\mathrm{GeO}_{2}$ [14], 5 - сапфировые [15-16], $6 a-$ на основе $\mathrm{As}_{2} \mathrm{~S}_{3}$ [9,10], $6 b-$ на основе $\mathrm{As}_{2} \mathrm{Se}_{3}[9,11], 6 c-$ на основе $\mathrm{Ga}-\mathrm{As}-\mathrm{Te}-\mathrm{Se}[9]$.

$(0.8-2.0 \mu \mathrm{m})$, где применяются кварцевые волокна, до средней и даже дальней ИК области (до $100.0 \mu \mathrm{m}$ ) обосновывает поиск новых оптических материалов, разработку технологий их синтеза, исследование структуры, свойств и областей применения. Поэтому актуальной задачей является разработка радиационностойких, негигроскопичных и пластичных кристаллов для изготовления световодов среднего ИК диапазона.

В связи с этим представляло интерес исследовать четырехкомпонентную систему $\mathrm{AgBr}-\mathrm{AgI}-\mathrm{TlBr}-\mathrm{TlI}$, в частности еe квазибинарные сечения $\mathrm{AgBr}-\mathrm{TlI}$ и $\mathrm{AgBr}-\mathrm{TlBr}_{0.46} \mathrm{I}_{0.54}$. Данный выбор был обоснован схожими физико-химическими свойствами фазовых диаграмм плавкости систем $\mathrm{AgCl}-\mathrm{AgBr}$ и $\mathrm{TlBr}-\mathrm{TlI}$, в которых образуется непрерывный ряд твердых растворов замещения и которые плавятся при более низкой температуре $\left(412\right.$ и $\left.419^{\circ} \mathrm{C}\right)$, чем исходные компоненты $[29,30]$.

В Уральском федеральном университете имени первого Президента России Б.Н. Ельцина создан инновационно-внедренческий центр „Центр инфракрасных волоконных технологий“ (ИВЦ „ЦИВТ“), деятельностью которого является проведение фундаментальных и прикладных исследований в области разработки элементной базы фотоники, лазерной техники, микрои оптоэлектроники, волоконной оптики среднего ИК диапазона. Разработан новый класс кристаллов систем $\mathrm{AgBr}-\mathrm{TII}$ и $\mathrm{AgBr}-\mathrm{TlBr}_{0.46} \mathrm{I}_{0.54}$, представленный в настоящей работе, исследуются также полученные ранее системы на основе галогенидов серебра [23,31]. Разрабатывается и внедряется полный технологический цикл, включающий проектирование и изготовление нестандартного оборудования по синтезу высокочистого сырья, росту кристаллов, получению микроструктурированных ИК световодов и созданию волоконнооптических систем широкого применения [32]. Ключевые этапы производства кристаллов, оптических изделий, ИК световодов и области применения представлены на рис. 2.

\section{Технология получения ИК кристаллов}

Решением первой и основной стадии синтеза кристаллов является получение высокочистых сложного состава твердых растворов гидрохимическим методом, названным авторами ТЗКС - термозонной кристаллизацией синтезом [33]. Метод сочетает в себе синтез и глубокую очистку конечного продукта (доля примесей $10^{-6}-10^{-7}$ wt.\% и менеe). В широком понимании метод ТЗКС является базовым при получении малорастворимых высокочистых веществ двух категорий индивидуальных галогенидов металлов типа MeHal, где $\mathrm{Me}-\mathrm{Ag}^{+}, \mathrm{Tl}^{+}, \mathrm{Cu}^{+}$; $\mathrm{Hal}-\mathrm{Cl}^{-}, \mathrm{Br}^{-}, \mathrm{I}^{-}$, и их твердых растворов $\mathrm{AgCl}-\mathrm{AgBr}, \mathrm{AgCl}-\mathrm{AgBr}-\mathrm{AgI}$ (TlI), $\mathrm{AgBr}-\mathrm{AgI}, \mathrm{AgBr}-\mathrm{TlI}, \mathrm{AgBr}-\mathrm{TlBr}_{0.46} \mathrm{I}_{0.54}$ и других. Кроме того, метод ТЗКС является экологически чистым, безотходным (выход высокочистого продукта составляет до $98.0 \%$ ) и энергосберегающим. Его целесообразно рассматривать с позиции равновесной и неравновесной термодинамики. Говоря о гидрохимическом методе получения твердых растворов, следует иметь в виду все многообразие его вариантов. Различие между ними определяется главным образом выбором исходных веществ, смешивание которых приводит к запуску процесса получения твердого раствора задаваемого состава. На этой основе построена математическая модель синтеза твердых растворов галогенидов металлов из водных сред галогенводородных кислот, позволяющая производить теоретические расчеты с заданным содержанием компонентов. Достоверность модели подтверждена экспериментально [34].

Авторским коллективом ИВЦ „ЦИВТ“ сконструирована и изготовлена ростовая установка ПКБ - печь конструкции Бриджмена, реализующая две задачи: выращивание монокристаллов и термодинамическое изучение фазовых диаграмм на основе многокомпонентных систем методом дифференциально термического анализа (ДТА) (рис. 3). Установка ПКБ имеет 4 зоны нагрева и разделительную диафрагму, которая обеспечивает температурный градиент на границе „расплав-кристалл“ до $60^{\circ} \mathrm{C}$ на $1 \mathrm{~cm}$. Автоматизированный блок управления позволяет контролировать температуру в диапа- 


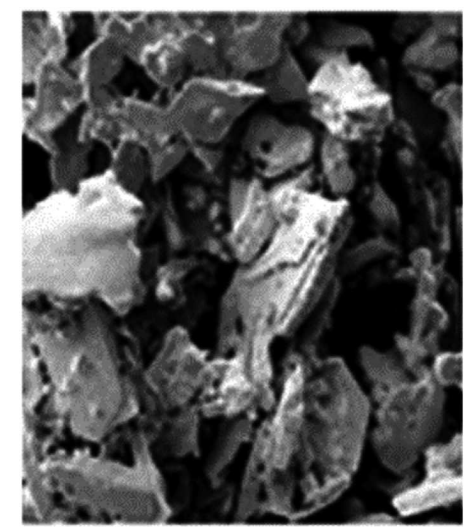

Polycrystalline charge

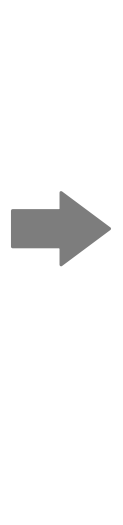

Single crystal $\mathrm{AgCl}-\mathrm{AgBr}, \mathrm{AgBr}-\mathrm{TlI}$, $\mathrm{AgBr}-\mathrm{TlBr}_{0.46} \mathrm{I}_{0.54}$
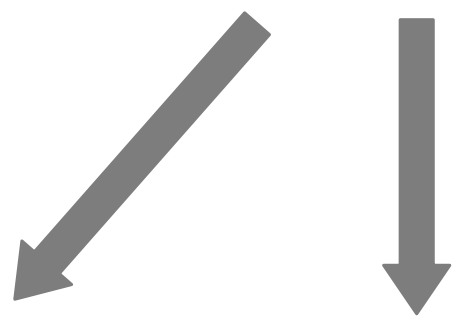

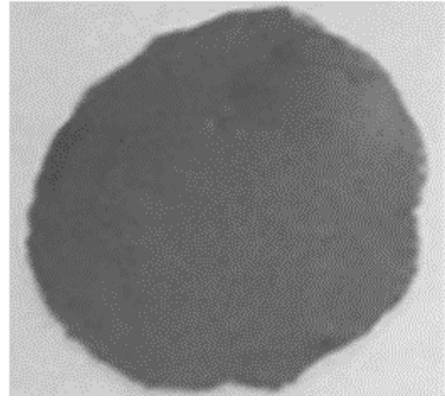

Windows

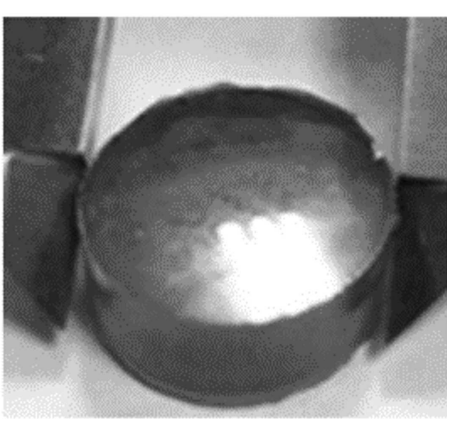

Lenses
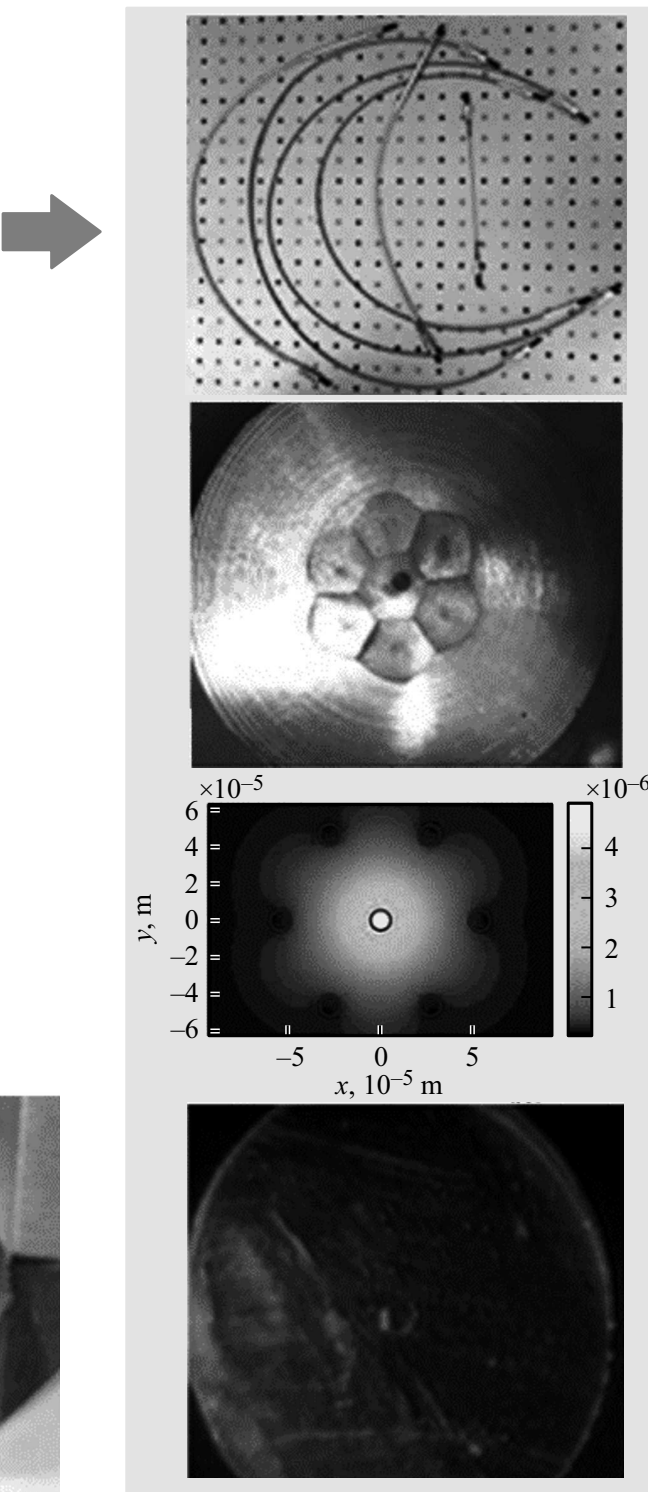

IR fibers

Application

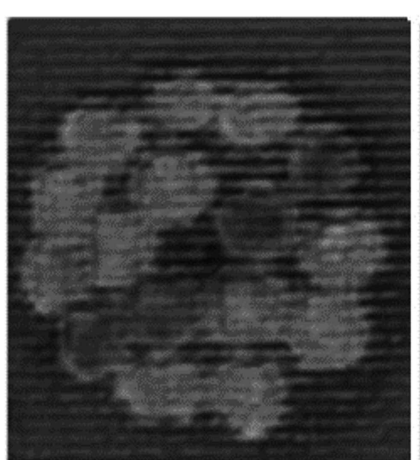

Low-temperature IR pyrometry

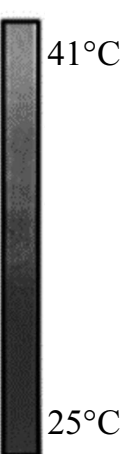

$5^{\circ} \mathrm{C}$

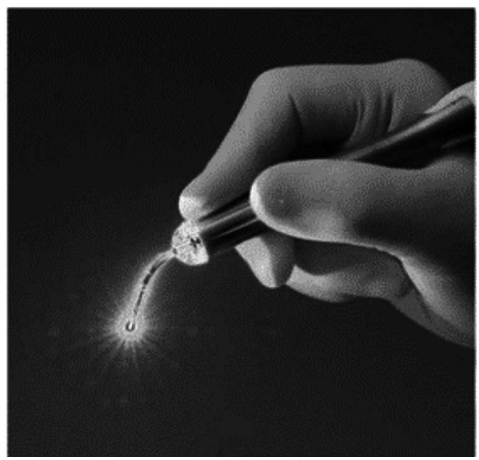

Laser technology and medicine

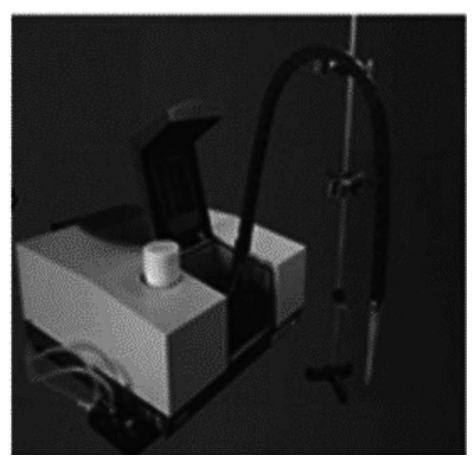

IR spectroscopy

Рис. 2. Этапы производства кристаллов, оптических изделий, ИК световодов и области применения. 

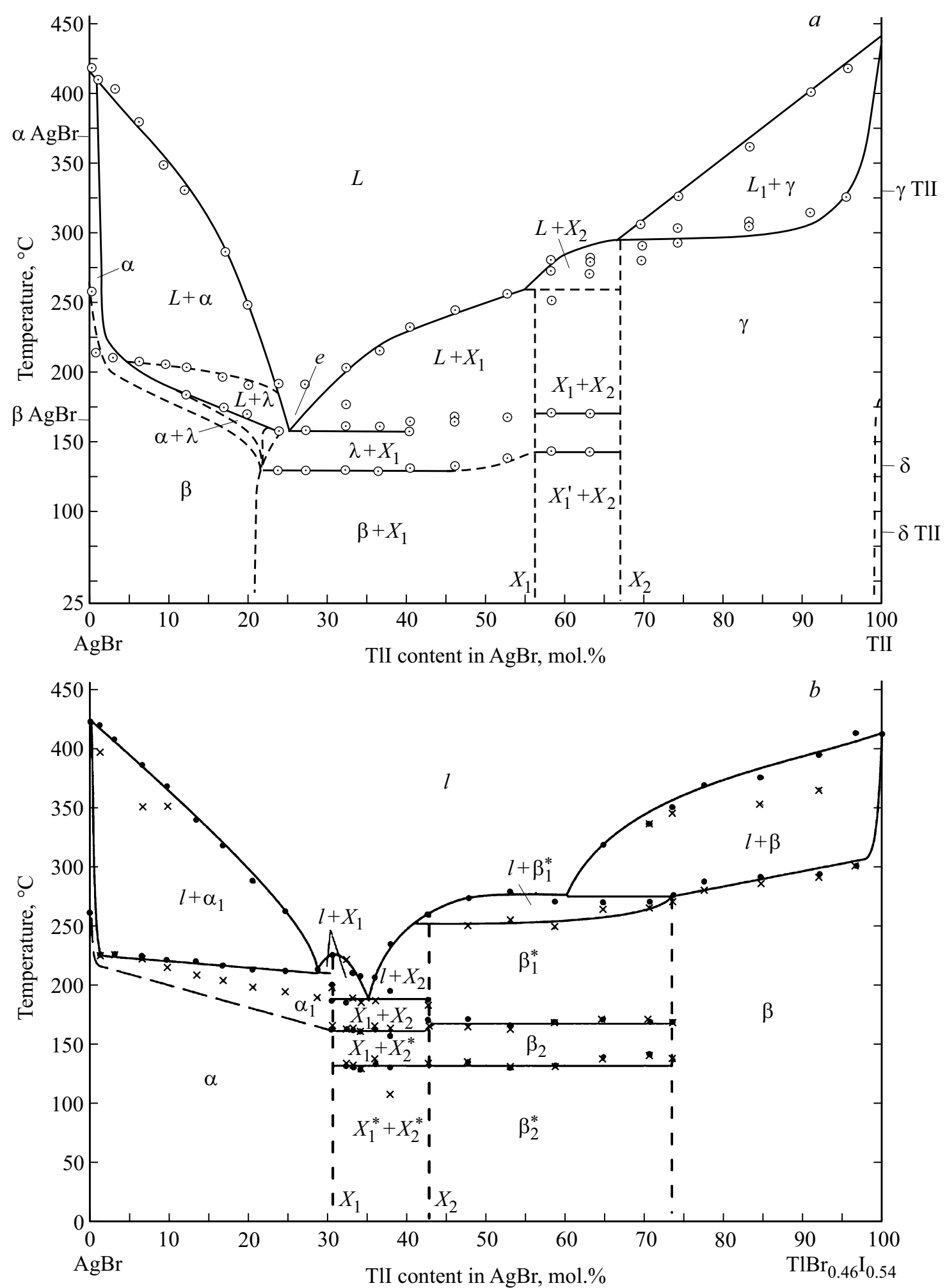

Рис. 3. Концентрационный тетраэдр $\mathrm{Ag}-\mathrm{I}-\mathrm{Br}-\mathrm{Tl}:(a)$ квазибинарное политермическое сечение системы $\mathrm{AgBr}-\mathrm{TlI} ;(b)$ квазибинарное политермическое сечение системы $\mathrm{AgBr}-\mathrm{TlBr}_{0.46} \mathrm{I}_{0.54} ;(c)$ изотермический разрез $\mathrm{AgBr}-\mathrm{AgI}-\mathrm{TlBr}-\mathrm{TII}$ с политермической разверткой граничных фазовых диаграмм.

зоне от 150 до $600^{\circ} \mathrm{C}$ с точностью $0.1^{\circ}$. Управление и контроль процессом выращивания монокристаллов осуществляется с помощью компьютера [35]. Для вы- ращивания кристаллов на основе твердых растворов галогенидов серебра и одновалентного таллия подобрано более ста режимов роста. 


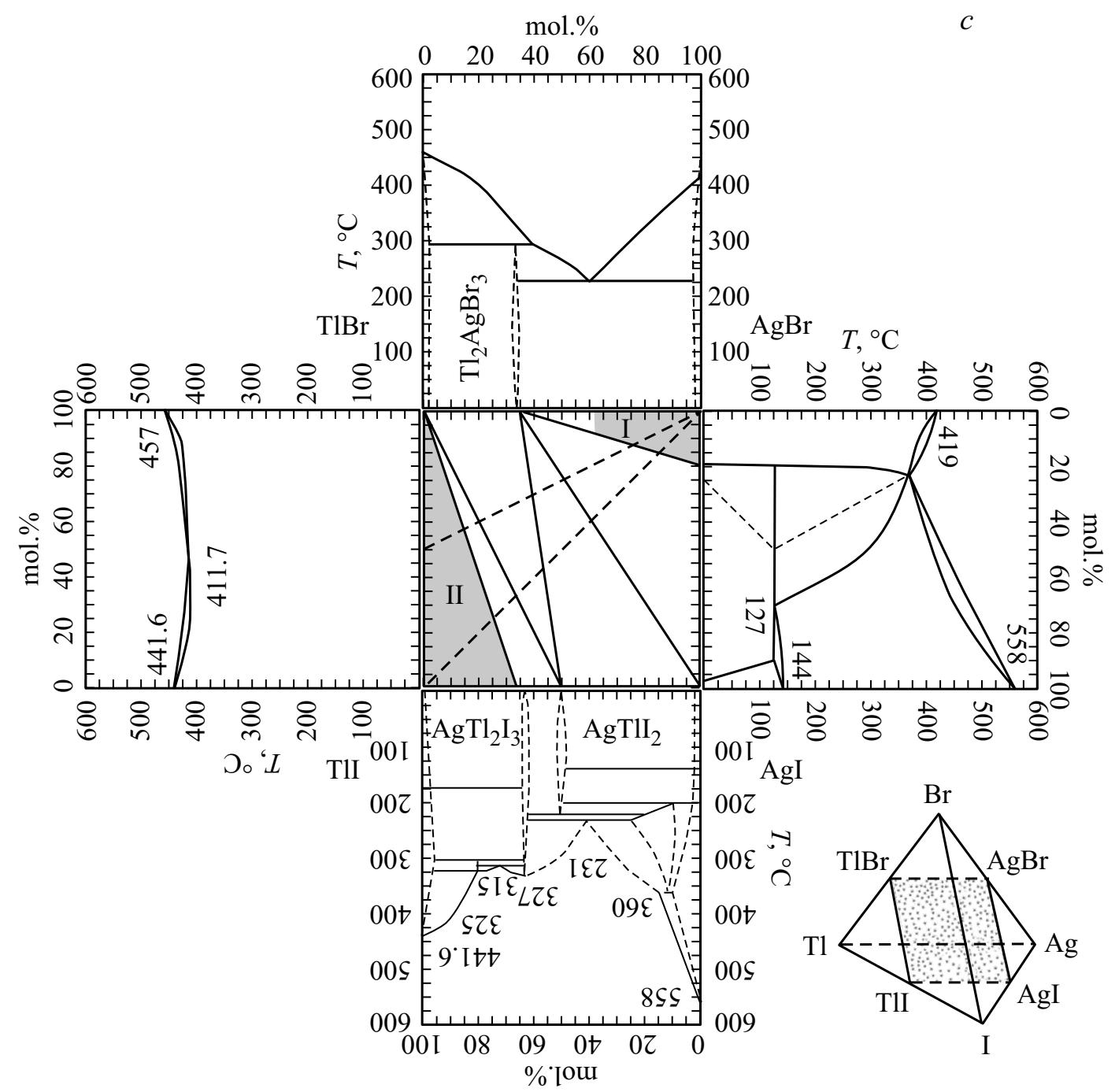

Рис. 3 (продолжение).

Разработан комплекс новых экспериментальных методик для определения показателя преломления $(n)$ в зависимости от длины волны: интерференционным методом, спектроскопическим методом и методом определения $n$ по коротковолновому краю поглощения согласно формуле Мосса. Разработаны методики для определения фотои радиационной стойкости кристаллов и ИК световодов.

Новый класс кристаллов предназначен в основном для получения различной структуры волокон среднего ИК диапазона спектра, а также для изготовления оптических изделий - линз, окон, оптических слоев, пленок. Для сокращения и упрощения производственного цикла получения кристаллических ИК световодов и микроструктурированных волокон различной геометрии применяется компьютерное моделирование структур с помощью программного пакета SMTP (Source-Model Technique Package - методика моделирования источников света) [36]. Моделирование структуры позволяет определить геометрические размеры волокна (кольца периферических вставок с низким показателем преломления и центральный дефект с низким или высоким $n$ либо его отсутствием), выбрать состав кристаллов и установить те наборы параметров, при которых достигается концентрирование проходящего по волокну излучения в центральной его части на различных длинах волн.

\section{Термодинамическое исследование диаграмм плавкости систем $\mathrm{AgBr}-\mathrm{Tll}$ и $\mathrm{AgBr}-\mathrm{TIBr}_{0,46} \mathrm{I}_{0,54}$}

Изучение фазовой диаграммы $\mathrm{AgBr}-\mathrm{TlI}$ методами дифференциально-термического и рентгеноструктурного анализов (ДТА, РФА) проводились в несколько этапов. На первом этапе была изучена область до $12 \mathrm{wt} . \%$ (8 mol.\%) TII в AgBr [33,37], в которой было установлено существование твердых растворов замещения на основе $\mathrm{AgBr}$, структурный тип $\mathrm{NaCl}$. Успеш- 

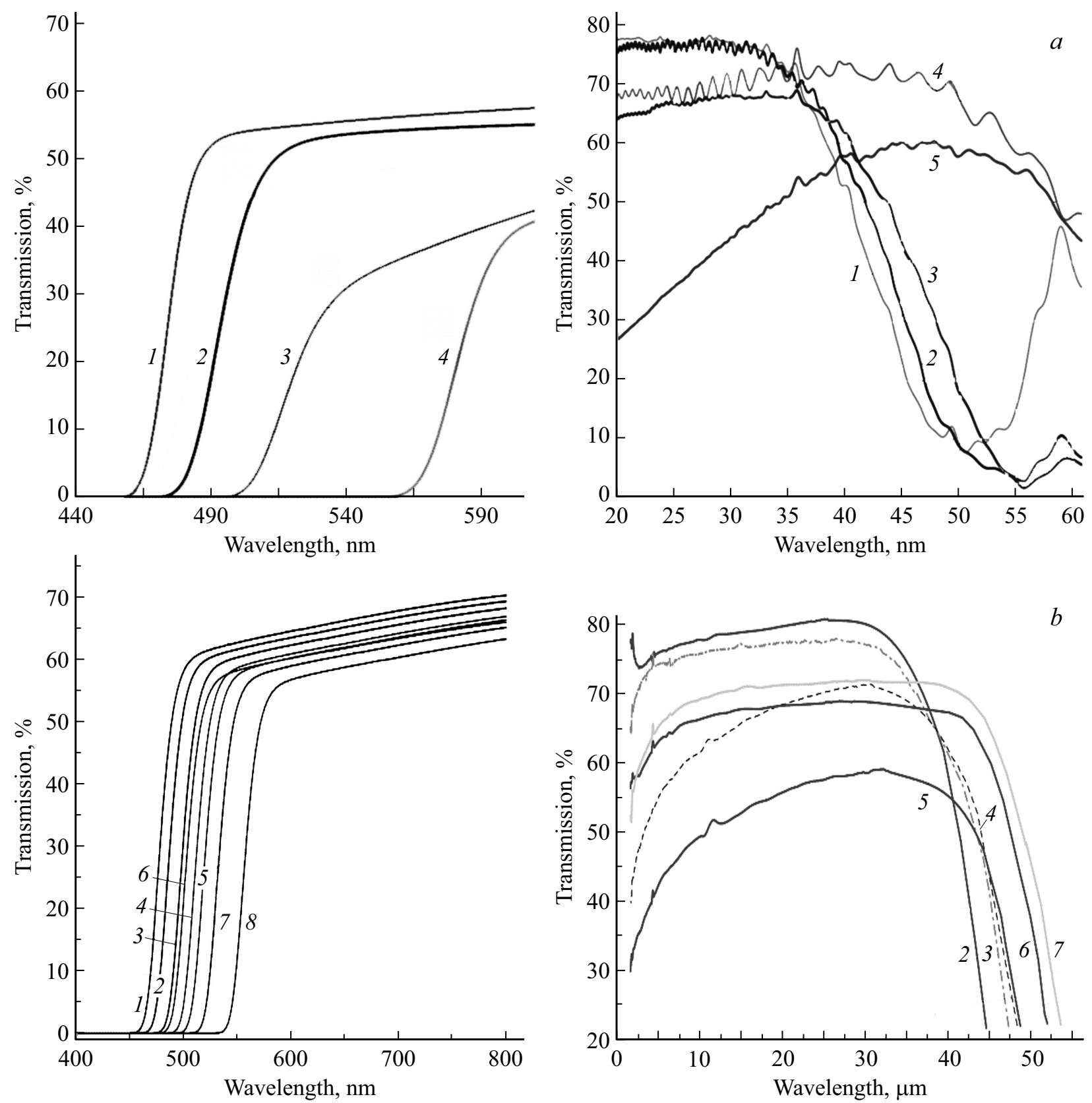

Рис. 4. Спектры пропускания кристаллов систем: (a) AgBr TlI: $1-\mathrm{AgBr} ; 2-5$ mol.\% TlI в $\mathrm{AgBr} ; 3-12 \mathrm{~mol} \% \mathrm{TlI}$ в $\mathrm{AgBr} ; 4-$ 83 mol.\% TII в AgBr; 5 - TII; $(b) \mathrm{AgBr}-\mathrm{TlBr}_{0.46} \mathrm{I}_{0.54}: 1$ - $\mathrm{AgBr} ; 2-1$ mol.\% $\mathrm{TlBr}_{0.46} \mathrm{I}_{0.54}$ в $\mathrm{AgBr} ; 3-5 \mathrm{~mol}^{2} \mathrm{TlBr}_{0.46} \mathrm{I}_{0.54}$ в $\mathrm{AgBr}$; 4 - 10 mol.\% $\mathrm{TlBr}_{0.46} \mathrm{I}_{0.54}$ в $\mathrm{AgBr} ; 5-29$ mol.\% $\mathrm{TlBr}_{0.46} \mathrm{I}_{0.54}$ в $\mathrm{AgBr} ; 6-78$ mol.\% $\mathrm{TlBr}_{0.46} \mathrm{I}_{0.54}$ в $\mathrm{AgBr} ; 7-92 \mathrm{~mol} \% \mathrm{TlBr}_{0.46} \mathrm{I}_{0.54}$ в $\mathrm{AgBr}$.

ное получение кристаллов этих составов со свойствами, значительно превосходящими как чистый $\mathrm{AgBr}$, так и широко известную систему твердых растворов $\mathrm{AgCl}-\mathrm{AgBr}$, показало перспективность исследования системы AgBr-TII [37,38]. Второй этап исследований был посвящен достаточно широкому изучению фазовой диаграммы во всем диапазоне составов с содержанием TlI в $\mathrm{AgBr}$ от 0 до $100 \mathrm{wt} \% \%$ с шагом $10 \mathrm{wt} . \%$. На этом этапе было установлено, что область существования устойчивых твердых растворов замещения на основе $\mathrm{AgBr}$ со структурным типом $\mathrm{NaCl}$ простирается до $20 \mathrm{wt} . \%$ TII в $\mathrm{AgBr}$ [38]. Однако возникла проблема корректировки режимов при выращивании кристаллов, соответствующих составам этой области, а также большему содержанию TII в $\mathrm{AgBr}$. Неверно определенные, по диаграмме, режимы роста кристаллов могут вызвать фазовые превращения, которые не только значительно ухудшают оптические свойства, но и делают материал непригодным для использования в оптике. В связи с этим встала задача более подроб- 

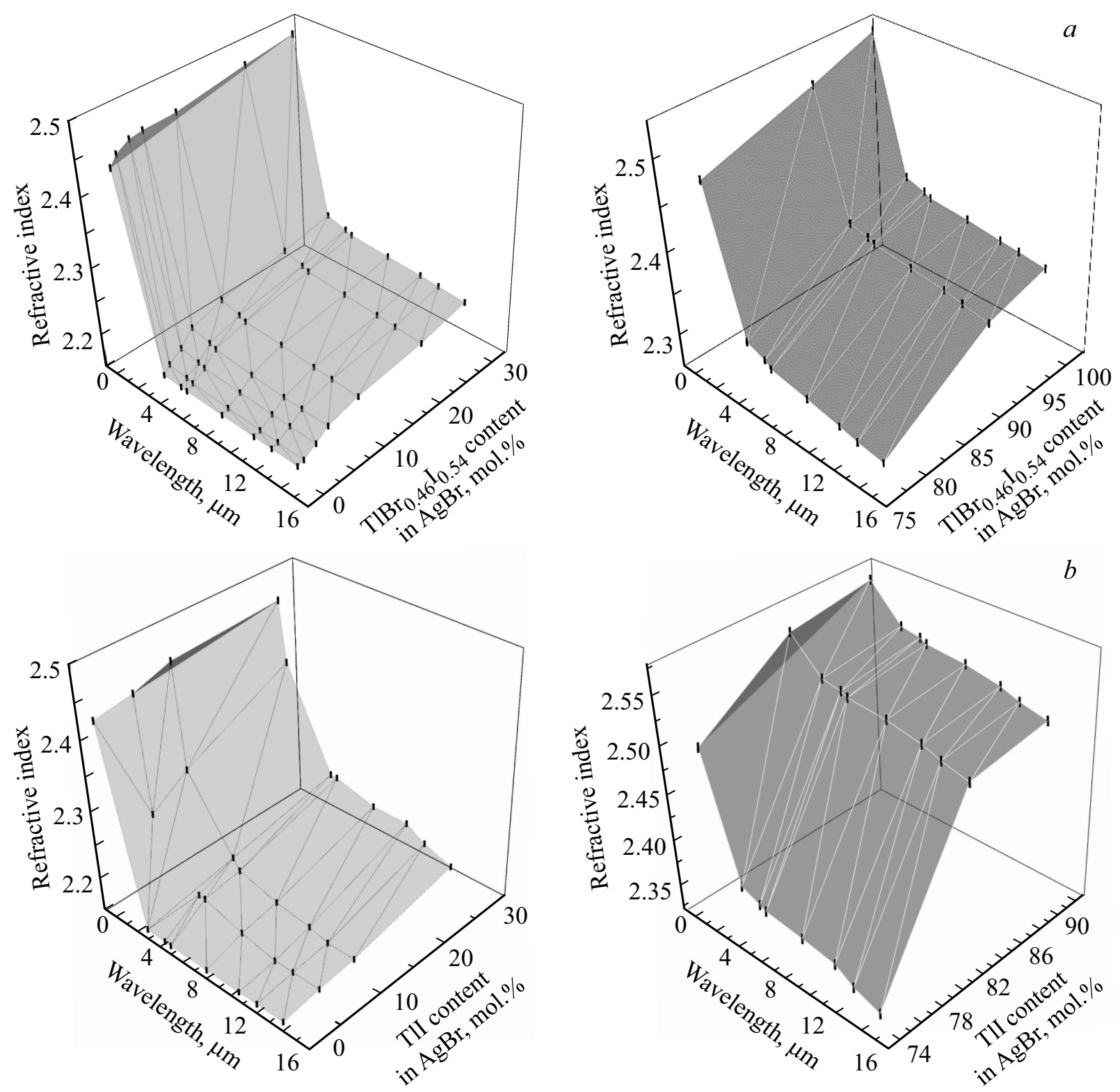

Рис. 5. Дисперсия показателя преломления для систем: (a) $\mathrm{AgBr}-\mathrm{TlBr}_{0.46} \mathrm{I}_{0.54} ;$ (b) $\mathrm{AgBr}-\mathrm{TII}$.

ного изучения системы $\mathrm{AgBr}-\mathrm{TlI}$ во всем концентрационном интервале от 0 до $100 \mathrm{~mol} \%$ TII в $\mathrm{AgBr}$ и исследованию характера взаимодействия компонентов в системе. Третий этап исследований заключался в исследовании фазовой диаграммы во всем диапазоне составов с содержанием TII в $\mathrm{AgBr}$ от 0 до $100 \mathrm{wt} . \%$ с шагом $5 \mathrm{wt.} \%$ в температурном диапазоне от 25 до $450^{\circ} \mathrm{C}$ при $1 \mathrm{~atm}$. На этом этапе была обнаружена область существования твердого раствора замещения в правой части диаграммы на основе TII, структурный тип $\mathrm{CsCl}$. Эта область находится в диапазоне составов от 67 до 100 mol.\% TII в $\mathrm{AgBr}$ (рис. 3,a). Таким образом, в системе $\mathrm{AgBr}-\mathrm{TII}$ в правой части диаграммы стабилизация кубической высокотемпературной модифи- кации йодида таллия (I) достигается добавлением до 33 mol.\% $\mathrm{AgBr}$ [35].

Кроме того, на третьем этапе была сформулирована идея рассмотрения данной фазовой диаграммы в качестве квазибинарного сечения разреза $\mathrm{AgBr}-\mathrm{AgI}-$ - TIBr-TII концентрационного тетраэдера $\mathrm{Ag}-\mathrm{Tl}-\mathrm{Br}-\mathrm{I}$ (рис. 3,c). Этому разрезу также принадлежит квазибинарная система $\mathrm{AgBr}-\mathrm{TlBr}_{0.46} \mathrm{I}_{0.54}$ (рис. $3, b$ ), которая исследовалась аналогично системе $\mathrm{AgBr}-\mathrm{TII}$ [39].

Штриховые линии на рис. 3, - - квазибинарные системы $\mathrm{AgBr}-\mathrm{TII}$ и $\mathrm{AgBr}-\mathrm{TlBr}_{0.46} \mathrm{I}_{0.54}$; сплошные линии предполагаемые каноды; область I - область составов, в которой предположительно возможно выращивать монокристаллы на основе $\mathrm{AgBr}$, структурный тип $\mathrm{NaCl}$; 


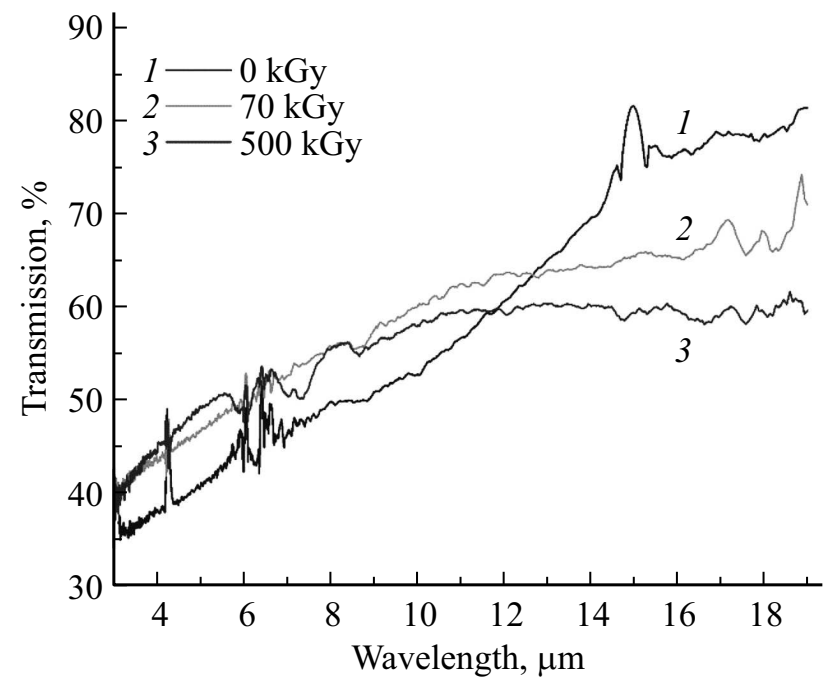

Рис. 6. Спектры пропускания ИК световодов системы $\mathrm{Ag}_{0.95} \mathrm{Tl}_{0.05} \mathrm{Br}_{0.95} \mathrm{I}_{0.05}$ при различных дозах ионизирующего излучения: $0(1),-70$ (2) и $500 \mathrm{kGy}(3)$.

область II - область, в которой предположительно возможно выращивать монокристаллы на основе $\mathrm{TlBr}-\mathrm{TlI}$, структурный тип $\mathrm{CsCl}$.

\section{Оптические свойства кристаллов}

Основной характеристикой новых кристаллов является диапазон оптической прозрачности. Исследования проводились на поликристаллических и монокристаллических пластинках толщиной $0.35-3.0 \mathrm{~mm}$ в диапазонах длин волн 0.19-1.10 $\mu \mathrm{m}$ (УФ спектрофотометр Shimadzu UV-1800), 1.28-41.60 (ИК фурье-спектрометр IRPrestige-21 Shimadzu), 14.00-61.00 $\mu \mathrm{m}$ (ИК фурьеспектрометр VERTEX 80 Bruker). Полученные результаты представлены на рис. 4. Было установлено, что в зависимости от содержания в кристаллах тяжелых по молекулярной массе TII в системе $\mathrm{AgBr}$ - TlI диапазон пропускания для длинноволнового края поглощения сдвигается до $50.0-61.0 \mu \mathrm{m}$, а в системе $\mathrm{AgBr}-\mathrm{TlBr}_{0.46} \mathrm{I}_{0.54}$ - до $45.0-50.0 \mu \mathrm{m}$.

Показатели преломления кристаллов для различных длин волн определяли спектроскопическим методом на ИК фурье-спектрометре. При измерении спектров плоскопараллельных пластин наблюдается интерференция, обусловленная отражением луча от противоположных стенок пластинки. Этот эффект использовали для определения показателя преломления кристаллов. С увеличением содержания галогенидов одновалентного таллия показатель преломления в кристаллах возрастает во всем диапазоне длин волн (рис. 5). На рис. 5 приведена дисперсия показателя преломления для кристаллов систем $\mathrm{AgBr}-\mathrm{TlI}$ и $\mathrm{AgBr}-\mathrm{TlBr}_{0.46} \mathrm{I}_{0.54}$ в диапазоне волн от 0.46 до $14.0 \mu \mathrm{m}$.
Впервые проведено экспериментальное исследование воздействия ионизирующего излучения на ИК световоды системы AgBr-TII (рис. 6). Представлена зависимость оптических потерь ИК световодов от дозы поглощенного ионизирующего $\gamma$-излучения. Установлен просветляющий эффект при поглощенных дозах 70 и $500 \mathrm{kGy}$ для исследуемой системы в диапазоне длин волн 4-11 $\mu \mathrm{m}$ [35].

Кроме того, проведено изучение радиационной стойкости кристаллов системы $\mathrm{AgBr}-\mathrm{TlBr}_{0,46} \mathrm{I}_{0,54}$ (рис. 7) при поглощенной дозе ионизирующего излучения $100 \mathrm{kGy}$. Установлено, что для кристаллов 10, 78 и 100 mol.\% $\mathrm{TlBr}_{0,46} \mathrm{I}_{0,54}$ в $\mathrm{AgBr}$ наблюдается повышение уровня пропускания от 0.7 до $5.3 \%$ (значения ниже нулевой линии на рис. 7) в зависимости от состава и длины волны.

\section{Моделирование структуры ИК световодов}

Моделирование фотонной структуры и модового состава ИК волоконных световодов осуществлялось с помощью программы SMT [36]. Выполнялся поиск оптимальных структур световодов для поддержания одномодового режима на длине волны $10.6 \mu \mathrm{m}$ с максимально большей площадью поля моды [40]. Располагая набором показателей преломления на $10.6 \mu \mathrm{m}$ для различных содержаний бромида серебра в $\mathrm{AgCl}-\mathrm{AgBr}$ и монойодида таллия в $\mathrm{AgBr}-\mathrm{TII}$, составы были разбиты на три группы, по три состава каждая, следующим образом: 1-й состав - $\mathrm{AgCl}_{0.25} \mathrm{Br}_{0.75}(n=2.123)$, $\mathrm{AgCl}_{0.18} \mathrm{Br}_{0.82} \quad(n=2.130), \mathrm{AgCl}_{0.16} \mathrm{Br}_{0.84} \quad(n=2.134)$; 2-й состав - $\mathrm{AgBr}(n=2.166), \mathrm{Ag}_{0.99} \mathrm{Tl}_{0.01} \mathrm{Br}_{0.99} \mathrm{I}_{0.01}$ $(n=2.173), \quad \mathrm{Ag}_{0.98} \mathrm{Tl}_{0.02} \mathrm{Br}_{0.98} \mathrm{I}_{0.02} \quad(n=2.186) ; 3$-й состав - $\mathrm{AgCl}(n=1.988), \mathrm{AgCl}_{0.86} \mathrm{Br}_{0.14} \quad(n=1.997)$, $\mathrm{AgCl}_{0.60} \mathrm{Br}_{0.40}(n=2.055)$. Первый показатель преломления в каждой группе соответствовал периферическим

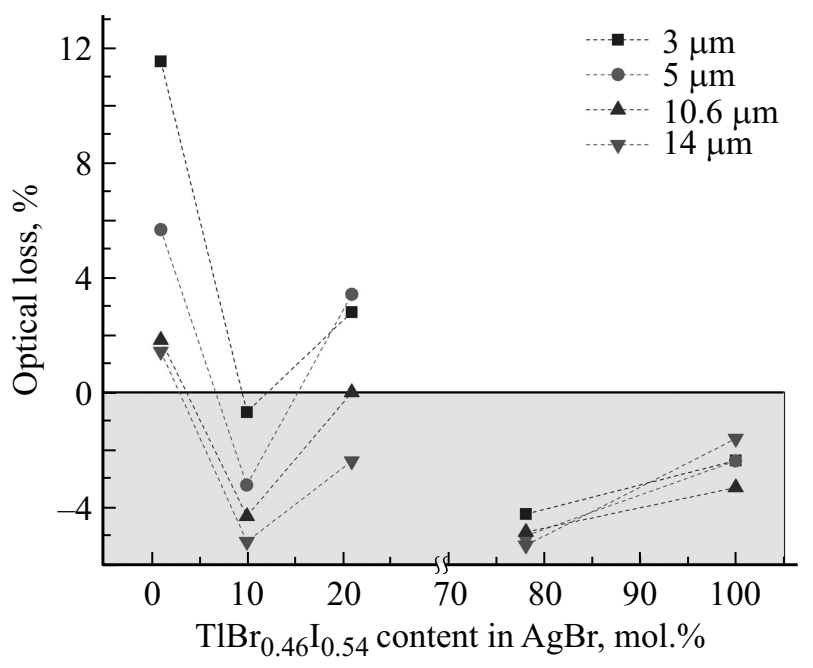

Рис. 7. Относительное изменение оптических потерь кристаллов системы $\mathrm{AgBr}-\mathrm{TlBr}_{0.46} \mathrm{I}_{0.54}$ при поглощенной дозе $100 \mathrm{kGy}$. 


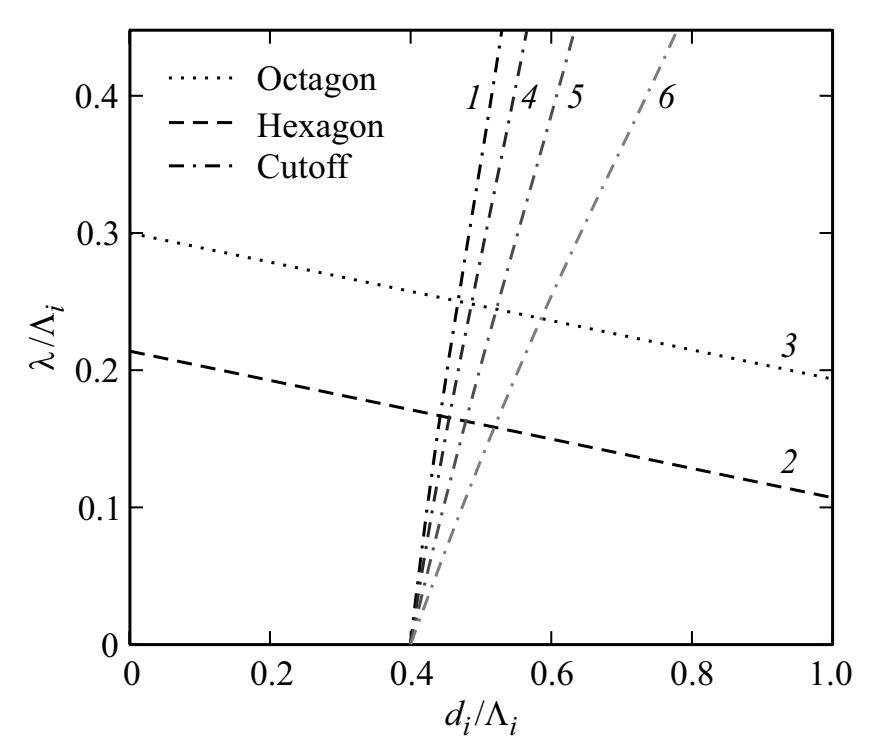

Рис. 8. Фазовая диаграмма „бесконечный“ одномодовый режим-многомодовый режим: 1 - граница раздела модовых режимов; 2 и 3 - прямые, содержащие наши экспериментальные точки (накладываются в случае двух колец вставок) при заданном варьировании относительного размера вставки, $\lambda=10.6 \mu \mathrm{m} ; 4-6$ - кривые перехода от структуры с отсутствием вставки в сердцевине к структурам с наличием центральной вставки с увеличенным показателем преломления при выбранных составах.

вставкам микроструктуры, второй - матрице, третий центральным вставкам (при наличии). Существующая зависимость для параметров границы раздела модовых режимов рассчитана для кварцевых волокон. Использован множитель Ренверсез [41] в формуле Кульмея [42], который учитывает в том числе возможность создания PCF из иных материалов:

$$
\left(\lambda / \Lambda_{i}\right)=2.80\left(d_{i} / \Lambda_{i}-0.406\right)^{0.89} \sqrt{\frac{\left(n_{m, e f, 1}^{2}-n_{i, 1}^{2}\right)}{\left(n_{m, e f, 2}^{2}-n_{i, 2}^{2}\right)}}
$$

где $n_{m, e f, j}$ и $n_{i, j}$ - эффективные показатели преломления матрицы и вставок при переходе от одного химического состава (подстрочный индекс 1) к другому составу (индекс 2). Для выбранных составов при переходе от твердотельных световодов с периферическими вставками к световодам с периферическими вставками и сердцевиной с увеличенным показателем преломления граница в области бо́льших нормализованных длин волн сдвигается вправо (кривые 4-6 на рис. 8). Помимо этого сильное влияние на режим оказывает вставка в центре структуры (рис. 9, $a-c$ ). Структура поддерживает одномодовый режим работы на длине волны $10.6 \mu \mathrm{m}$ за счет одновременного влияния механизмов фотонных запрещенных зон (ФЗ3) и полного внутреннего отражения (ПВО).

\section{Экструзия ИК фотонно-кристаллических световодов}

Разработан и реализован семистадийный алгоритм процесса экструзии при получении микроструктурированных волокон на основе кристаллов твердых растворов галогенидов серебра и таллия (I) (рис. 10), преду-

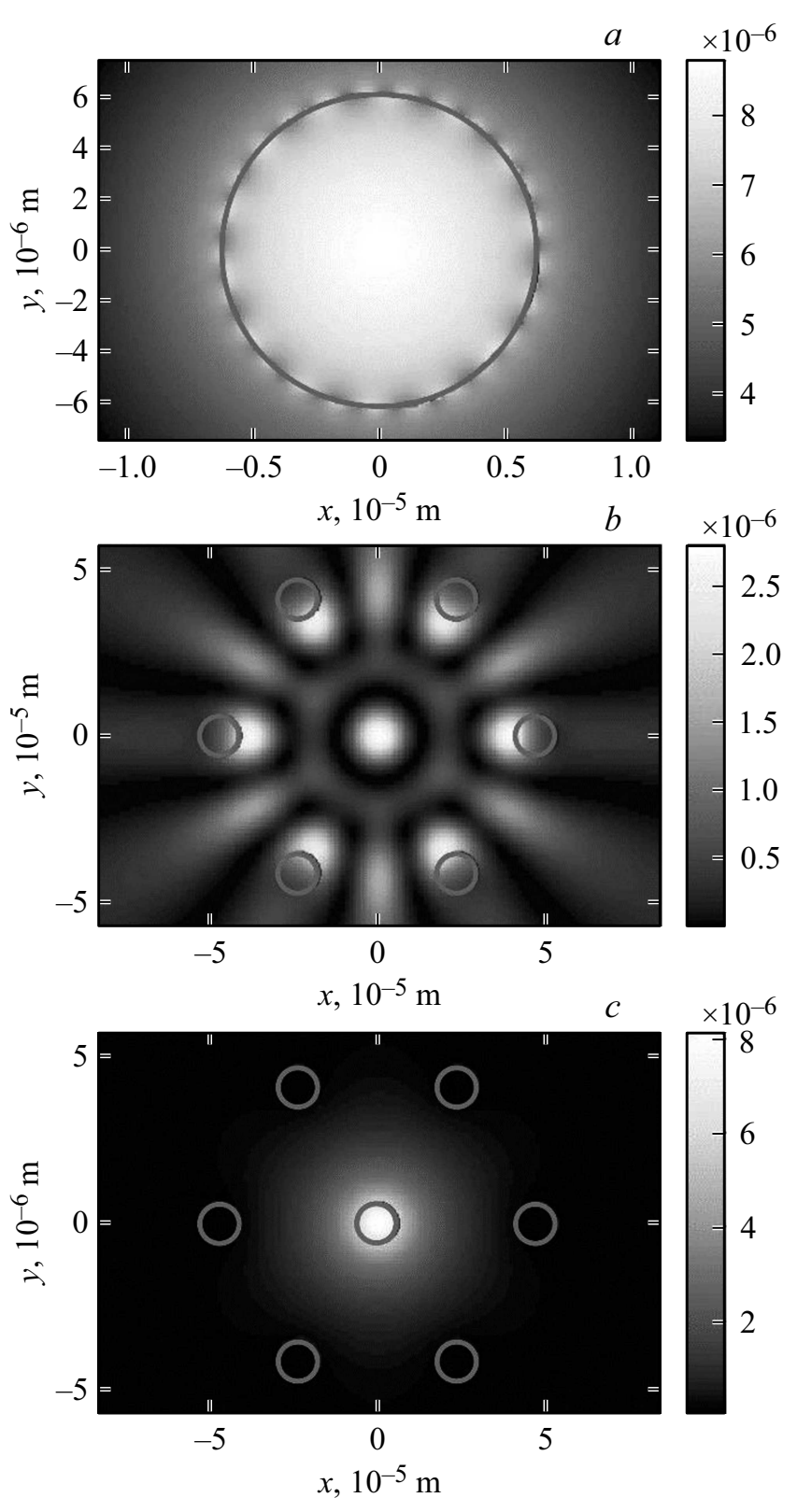

Рис. 9. Результаты моделирования световодов с диаметрами вставок $13 \mu \mathrm{m}$, межцентровым расстоянием $54 \mu \mathrm{m}$, составом периферических вставок $\mathrm{AgBr}_{0.83} \mathrm{Cl}_{0.17}$, матрицы $\mathrm{AgBr}_{0.98} \mathrm{Cl}_{0.02}$, центральной вставки $1 \mathrm{~mol} \%$ TlI в $\mathrm{AgBr}:(a)$ одномодовый двуслойный световод с диаметром поля моды $22 \mu \mathrm{m}$, механизм ПВО; $(b)$ одномодовый РСF с модой высокого порядка и расположенными в гексагональном порядке вставками, работающий по принципу Ф33; $(c)$ одномодовый РСF с центральной вставкой с максимальным $n$, диаметр поля моды $100 \mu \mathrm{m}$, суперпозиция механизмов ФЗ3 и ПВО. 


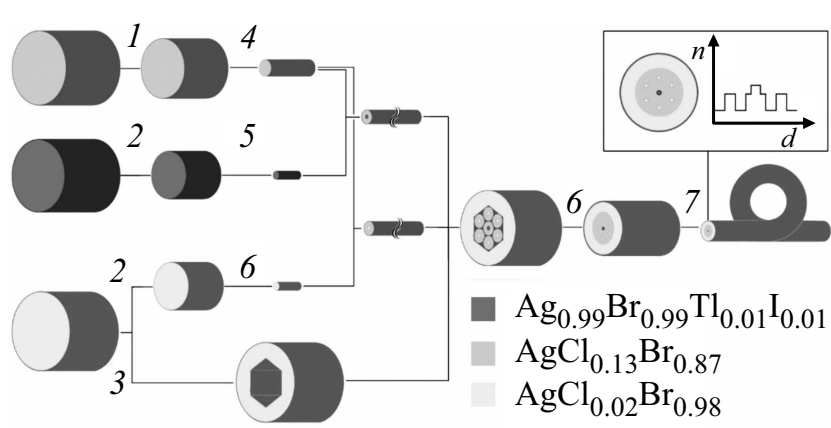

Рис. 10. Схема получения PCF с центральной вставкой с максимальным $n$. Цифрами обозначены этапы экструзии. На вставке показан профиль волокна и профиль его показателя преломления.

сматривающий этапы поочередной встречной экструзии преформ для создания продольной однородности микроструктуры. Разработана оснастка и подобраны режимы экструзии РСF. В соответствии с полученными результатами моделирования структуры одномодовых световодов изготовлены РCF с увеличенным диаметром поля моды на длине волны $10.6 \mu \mathrm{m}$.

\section{Применение}

Благодаря широкому диапазону прозрачности $(2.5-25 \mu \mathrm{m})$ и низким оптическим потерям ИК оптическое волокно делает возможным создание лабораторных и промышленных систем автоматизации, осуществляющих непрерывный контроль химического состава жидких и газовых сред на основе спектральных методов анализа. Для существующего в настоящее время волоконного спектрометра на основе систем $\mathrm{AgCl}-\mathrm{AgBr}$ [22] могут быть значительно расширены области применения в случае использования более фотои радиационно-стойкого оптического волокна. Станет возможным решение широкого спектра аналитических задач в условиях повышенного ионизирующего излучения: анализ „тяжелой воды“, анализ соединений урана, исследовательские работы в „горячих камерах“.

Развитие направления волоконно-оптического тепловидения позволит контролировать распределение температурных полей на изолированных и труднодоступных объектах в диапазоне температур от -150 до $+900^{\circ} \mathrm{C}$. Перспективным является создание волоконных сборок высокого разрешения для промышленных целей, в частности 3D печати, теплотехники, лазерной обработки материалов.

Рост потребности в надежных каналах доставки ИК излучения обусловлен развитием и разработкой новых параметрических генераторов света для среднего ИК диапазона [16].

\section{Выводы}

Оптические кристаллы на основе твердых растворов систем $\mathrm{AgBr}$ - TlI и $\mathrm{AgBr}-\mathrm{TlBr}_{0.46} \mathrm{I}_{0.54}$ по совокупности оптических и механических свойств занимают ведущие позиции среди разрабатываемых в настоящее время ИК материалов, предназначенных для производства оптических световодов для среднего ИК диапазона спектра. Разработаны научные основы технологии производства фотонно-кристаллических световодов на базе галогенидов серебра и таллия (I), исследованы функциональные свойства кристаллов, световодов и созданы на их основе волоконно-оптические устройства для среднего ИК диапазона спектра. Разработанные технологии и оборудование для синтеза сырья, роста кристаллов и экструзии ИК световодов позволяют развивать новую элементную базу фотоники и ИК волоконной оптики.

Выполнено исследование фазовых диаграмм систем $\mathrm{AgBr}-\mathrm{TlI}$ и $\mathrm{AgBr}-\mathrm{TlBr}_{0.46} \mathrm{I}_{0.54}$ в диапазоне температур от 25 до $450^{\circ} \mathrm{C}$ при давлении $1 \mathrm{~atm}$ с шагом $5 \mathrm{wt} . \%$. Диаграммы являются политермическими сечениями изотермического разреза $\mathrm{AgBr}-\mathrm{AgI}-\mathrm{TII}-\mathrm{TlBr}$ концентрационного тетраэдра $\mathrm{Ag}-\mathrm{Br}-\mathrm{Tl}-\mathrm{I}$. Определены области существования устойчивых твердых растворов замещения для системы $\mathrm{AgBr}-\mathrm{TlI}$ : в левой части до $20 \mathrm{~mol} \%$ TlI в $\mathrm{AgBr}$ (структурный тип $\mathrm{NaCl}$ ) и в правой части до $33 \mathrm{~mol} \% \mathrm{AgBr}$ в $\mathrm{TII}$ (структурный тип $\mathrm{CsCl}$ ). Для системы $\mathrm{AgBr}-\mathrm{TlBr}_{0.46} \mathrm{I}_{0.54}$ обнаружено расширение области гомогенности существования твердого раствора (структурный тип $\mathrm{NaCl}$ ) на основе $\mathrm{AgBr}$ с содержанием до $30 \mathrm{~mol}$ \% $\mathrm{TlBr}_{0.46} \mathrm{I}_{0.54}$.

Для выращенных кристаллов в широком концентрационном диапазоне составов измерены оптические свойства: диапазон пропускания и показатель преломления. При увеличении содержания TII и $\mathrm{TlBr}_{0.46} \mathrm{I}_{0.54}$ в $\mathrm{AgBr}$ диапазон прозрачности кристаллов расширяется в длинноволновую область - до $60 \mu \mathrm{m}$ и повышается показатель преломления. Выявлена стойкость ИК световодов состава $\mathrm{Ag}_{0.95} \mathrm{Tl}_{0.05} \mathrm{Br}_{0.95} \mathrm{I}_{0.05}$ к ионизирующему гаммаизлучению дозой до $500 \mathrm{kGy}$.

Плавное изменение показателя преломления в широком концентрационном интервале составов позволяет использовать материалы для создания фотоннокристаллических структур световодов,в том числе одномодовых с увеличенным до $100 \mu \mathrm{m}$ диаметром поля моды на длине волны $10.6 \mu \mathrm{m}$.

Исследование выполнено за счет гранта Российского научного фонда (проект № 18-73-10063).

\section{Список литературы}

[1] Miya T., Terunuma Y., Hosaka T., Miyashita T. // Electron. Lett. 1979. V. 15. P. 106.

[2] Качуяма T., Мацумура X. Инфракрасные волоконные световоды. М.: Мир, 1992. 272 с. 
[3] Raichlin Y., Katzir A. // App. Spectroscopy. 2008. V. 62. N 2. P. 55A.

[4] Жукова Л.В., Примеров Н.В., Корсаков А.С., Чазов А.И. // Неорг. мат. 2008. Т. 44. № 12. С. 1516.

[5] Harrington J.A. Infrared Fibers and Their Application. SPIE Press Monograph, 2003.

[6] Artyushenko V., Bocharnikov A., Sakharova T., Usenov I. // Optik \& Photonik. 2014. V. 4. P. 35.

[7] Sanghera J., Aggarwal I.D. Infrared Fiber Optics. CRC Press, 1998. 368 p.

[8] Корсаков А.С., Жукова Л.В., Львов А.Е., Салимгареев Д.Д., Корсаков М.С. // Оптический журнал. 2017. Т. 84. C. 80 .

[9] Волоконные световоды из высокочистых халькогенидных стекол [Электронный ресурс] Режим доступа: https://www.ihvv.org/svetovody-iz-halkogenidnyh

[10] IRFlex. IRF-S Series Chalcogenide MWIR Fibers (1.5 to $6.5 \mu \mathrm{m})$. [Электронный ресурс] Режим доступа: https://www.irflex.com/wp-content/uploads/sites/5696/2018/02/ IRflex-IRF-S-Series-MWIR-Fiber-Datasheet_V201801.web_.pdf

[11] Tao G. et al. // Adv. in Opt. and Photon. 2015. V. 7. P. 379.

[12] Thorlabs. Mid-Infrared Optical Fiber. [Электронный peсурс] Режим доступа: https://www.thorlabs.com/images/ /TabImages/ZrF4_InF3_Attenuation_Comparison.xlsx

[13] Poulain M., Poulain L. // Rev. Chim. Min. 1975. V. 12 (9). P. 1.

[14] Takahashi H., Sugimoto I. // J. Lightwave Tech. 1984. LT-2. P. 613.

[15] Alkor Technologies. IPL световоды из лейкосапфира. [Электронный ресурс] Режим доступа: http://www.alkor.net/alkorru/IPL_svetovod.html

[16] Калинцева Н.A., Серебряков В.А. Волоконные системы доставки излучения для медецинских лазеров среднего ИК диапазона: требования и параметры. [Электронный ресурс] Режим доступа: http://book.sarov.ru/wp-content/ /uploads/Lazer-X-2017-15.pdf

[17] Molex. Polymicro Technologies ${ }^{\mathrm{TM}}$ MediSpec $^{\mathrm{TM}}$ Hollow Silica Waveguide With Aiming Beam Technology. [Электронный ресурс] Режим доступа: https://www.cmscientific.com/info_sheets/hsw.pdf

[18] PIKE Technologies. Mid-IR FlexIR - Hollow Waveguide Accessory for Remote Infrared Sampling. [Электронный ресурс] Режим доступа: http://www.piketech.com/files/ /Catalog\%20Sections/PIKE_Catalog_RemoteSampling.pdf

[19] Harrington J.A. Infrared Fibers and Their Application. SPIE Press Monograph, 2004.

[20] CeramOptec. Optran MIR Fibers. [Электронный ресурс] Режим доступа: http://www.ceramoptec.com/products/fibers/optran-mir.html

[21] ART Photonics. Polycrystaline IR-Fibers. [Электронный peсурс] Режим доступа: https://artphotonics.com/product/polycrystaline-ir-fibers

[22] Mettler Toledo. ИК-Фурье-спектроскопия. [Электронный ресурс] Режим доступа: https://www.mt.com/int/ru/ /home/products/L1_AutochemProducts/ReactIR.html

[23] Artjushenko V.G., Butvina L.N., Vojtsekhovsky V.V., Dianov E.M. // Infrared Opt. Mat. and Fib. IV. 1986. V. 618. P. 103.

[24] Gal D., Eldar M., Valden R., Batler A., Neufeld H.N., Gaton E., Volman M., Akselrod S., Levite A., Katzir A. // Proc. SPIE. 1984. V. 494. P. 71. doi 10.1117/12.943912
[25] Shalem S., German A., Katzir A. // Proc. SPIE. 1995. V. 2631. P. 216. doi 10.1117/12.229185

[26] Shirakov A., Burshtein Z., Katzir A., Frumker E., Ishaaya A. // Opt. Exp. 2017. V. 26. N 9. P. 11694.

[27] Воронкова E.M. Оптические материалы для инфракрасной техники. М.: Наука, 1965. 335 с.

[28] Научные труды ГИРЕДМЕТА. Т. 29. М.: Металлургия, 1970. 159 c.

[29] Авдиенко К.И., Артюшенко В.Г., Белоусов А.С. Кристаллы галогенидов таллия: получение, свойства и применение. М.: Наука, 1989. 149 с.

[30] Korsakov A., Zhukova L., Korsakova E., Zharikov E. // J. Cryst. Growth. 2014. V. 386. P. 94.

[31] Artjushenko V.G., Vojtsekhovsky V.V., Kolesnikov Y.G., Konov V.I., Lerman A.A., Litvinenko E.G., Nikiforov S.M., Nabatov A.O., Zhukova L.V. // The Int. Soc. for Opt. Eng. 1989. V. 1048. P. 2.

[32] Центр инфракрасных волоконных технологий. [Электронный ресурc] Режим доступа: http://inno.urfu.ru// /text/show/centr-infrakrasnyh-volokonnyh-tehnologiy

[33] Корсаков А.С., Жукова Л.В., Жариков Е.В., Врублевский Д.С., Корсаков В.С. // Цвет. мет. 2010. № 1. С. 69.

[34] Гребнева А.А., Булатов Н.К., Жукова Л.В. // Неорг. мат. 2010. T. 46. № 6. С. 751.

[35] Корсаков В.С. Синтез кристаллов системы $\mathrm{AgBr}-\mathrm{TlI}$ : структура, свойства, применение. [Электронный pecypc] Режим доступа: http://lib.urfu.ru/mod/data/ /view.php?d=51\&rid=273194\&filter $=1$

[36] Hochman A., Leviatan Y. // J. Opt. Soc. Am. A. 2004. V. 21. N 6. P. 1073.

[37] Жукова Л.В., Корсаков А.С., Корсакова Е.А., Чазов А.И. // Расплавы. 2010. № 6. С. 76.

[38] Корсаков А.С., Жукова Л.В., Корсакова Е.А., Жуков В.В., Корсаков В.С. // Цвет. мет. 2013. № 4. С. 62.

[39] Корсаков А.С., Жукова Л.В., Корсаков В.С., Врублевский Д.С., Салимгареев Д.Д. // Цвет. мет. 2014. № 8. С. 50.

[40] Lvov A., Salimgareev D., Korsakov M., Korsakov A., Zhukova L. // Opt. Mat. 2017. V. 73. P. 337.

[41] Renversez G., Bordas F., Kuhlmey B.T. // Opt. Lett. 2005. V. 30. N 11. P. 1264.

[42] Kuhlmey B.T., McPhedran R.C., de Sterke C.M. // Opt. Lett. 2002. V. 27. N 19. P. 1684. 